\title{
$A$ SPÄTPHILOSOPHIE DE F. W. SCHELLING E O DESDOBRAR DA CONSCIENNCIA HUMANA
}

Cristiane A. de Azevedo* cris.a.azevedo@gmail.com

RESUMO Em 1821, Friedrich W. Schelling (1775-1854) inaugura um novo caminho para o seu pensamento. Esse novo caminho, como afirma o próprio filósofo, divide sua filosofia em duas partes, a saber, a filosofia negativa, que diz respeito a toda sua produção anterior, e a filosofia positiva que se inaugura a partir das aulas de Erlangen. Contudo, como veremos neste artigo, suas duas filosofias estão unidas na busca pelo pensamento da Unidade. Essa busca traduz-se na Spätphilosophie como busca do Absoluto. $O$ presente artigo tem como objetivo refletir sobre os escritos da chamada Filosofia da Mitologia que visam pensar o caminho do Absoluto. Tal caminho relaciona-se com o caminho percorrido pela própria consciência humana e, ao mesmo tempo, coincide com ela. Portanto, a análise culminará no que chamou de processo mitológico e sua relação com o politeísmo sucessivo, já que a mitologia teria se constituído graças à sucessão dos deuses efetuada na consciência humana.

Palavras-chave Absoluto, consciência, filosofia da mitologia, F. W. Schelling.

ABSTRACT In 1821, Friedrich W. Schelling (1775-1854) opens a new path for his thinking. This new path, as affirmed by the philosopher himself, he divides his philosophy in two parts: the negative philosophy, which concerns all his previous production, and the positive philosophy that is inaugurated by

* Professora da Faculdade São Bento-RJ. Artigo recebido em 14/03/2013 e aprovado em 20/10/2013.

KRITERION, Belo Horizonte, $n^{\circ}$ 130, Dez./2014, p. 549-560 
the Erlangen courses. However, both philosophies are linked together by the search of the thought of the Unity, a search manifested in the Spätphilosophie as the quest for the Absolute. The present article aims to reflect upon the writings of the so-called Philosophy of Mythology, which intends to think about the way to the Absolute. Such way is related to the path followed by the human conscience itself and, at the same time, it coincides with the conscience itself. Therefore, the analysis shall culminate in what Schelling called "mythological process" and in its relation with the successive polytheism, since mythology may have constituted itself by the succession of gods, effected in human conscience.

Keywords Absolute, conscience, philosophy of mythology, $F . \quad W$. Schelling.

Podemos situar a chamada filosofia tardia de Schelling a partir da retomada de suas atividades acadêmicas como professor em Erlangen, em 1821, seguida, posteriormente, pelas suas atividades em Munique, em 1827, e, finalmente, em 1841, em Berlim. Esse "novo começo", como o próprio Schelling nomeia, foi precedido por um longo período de reclusão em que o filósofo trabalhou exclusivamente na sua elaboração, sem dar aulas ou publicar. No entanto, essa passagem à chamada filosofia positiva não significou uma mudança brusca em seu pensamento e nem mesmo, como veremos, uma ruptura com sua obra anterior. Ao contrário, podemos dizer que o caminho para a filosofia positiva estava sendo traçado ao longo de sua obra; para Tilliette $(2002$, p. 41) essa passagem se encontrava já inscrita nas margens da sua Filosofia da identidade.

Essa retomada, contudo, despertou várias reações contraditórias. Alguns acreditavam que se tratava do reaparecimento do panteísmo da Naturphilosophie, outros só perceberam um pensamento retrógrado e confuso. Enquanto o hegelianismo de direita ridicularizou sua filosofia como uma má imitação do sistema, o hegelianismo de esquerda considerou-a uma teologia vergonhosa (Tilliette, 1992, pp. 11-12).

Mesmo após retomar suas aulas, Schelling nada publicou dessa última fase de seu pensamento. De 1812 até sua morte em 1854, ele só publica o texto sobre as Divindades de Samotrácia, o Prefácio para o livro de Victor Cousin e alguns breves textos acadêmicos. Como afirma Tilliette (ibidem, p. 14), o escritor compulsivo se transformou em temporizador; se, anteriormente, ele 
pecava pela precipitação, em sua última fase, peca pela omissão. Schelling proíbe e, até mesmo, se esforça para impedir a difusão de seus cursos. Portanto, tudo que temos dessa última filosofia foi publicado postumamente, sem que Schelling, apesar das indicações deixadas e de seu testamento literário, tenha tido a oportunidade da última revisão.

Sua obra tardia é composta em linhas gerais pela "Introdução históricocrítica da filosofia da mitologia" e pela "Exposição da filosofia racional pura" que compõem a "Introdução à Filosofia da mitologia"; a "Filosofia da mitologia", cujas seis primeiras lições compõem o escrito "O monoteísmo"; e a "Filosofia da Revelação" dividida em três tomos. ${ }^{1}$

Portanto, a Spätphilosophie foi exposta em cursos e conferências, é esse o material que temos, o que explica, segundo Tilliette (1992, t. 2, p. 16), o caráter didático dessa filosofia e suas inúmeras repetições. Essa característica faz com que nos deparemos com uma filosofia em constante movimento, repensada a cada semestre em um interminável processo de elaboração. A filosofia tardia de Schelling constitui-se em um constante processo, trata-se de um permanente caminhar do pensamento que não pode parar antes de encontrar aquilo que the faz caminhar e que se vê obrigado a revisar seu caminho a todo tempo. Essa busca é, como veremos, a busca pela unidade que, no pensamento tardio do filósofo, se traduz pela busca do Absoluto.

Schelling, não diferentemente de seus contemporâneos como Hegel e Fichte e seus antecessores, como Spinoza e Kant, assume também como sua a tarefa com a qual o pensamento se ocupou ao longo da história da filosofia. Trata-se de pensar a dualidade que, a partir do período moderno, traduziu-se pela contraposição entre sujeito e objeto, liberdade e necessidade, natureza e história, racionalismo e empirismo ou quais sejam as demais figuras que a dualidade encarnou ao longo da história da filosofia. Schelling irá empenharse em pensar essa dualidade na tentativa de resolvê-la, de buscar a unidade.

Contudo, o que acabamos de dizer soa contraditório quando nos voltamos para a obra de Schelling e vemos uma filosofia multifacetada, dividida em diferentes filosofias como filosofia da natureza, filosofia da identidade, filosofia da arte, filosofia da mitologia e filosofia da revelação. Ou ainda quando vemos o próprio Schelling esforçando-se por distinguir sua filosofia dos cursos de Erlangen da sua filosofia anterior: ao inaugurar, em 1821, esse novo começo

1 Essas obras encontram-se na edição das obras completas "Sämtliche Werke". Augsburg/Stuttgart: Cotta, 1856-1861. A "Introdução histórico-crítica da filosofia da mitologia" e a "Introdução à Filosofia da mitologia" correspondem a SW, XI; a "Filosofia da mitologia", SW, XII; e a "Filosofia da Revelação", SW, XIII e XIV. 
de seu pensamento, Schelling divide sua filosofia em duas, a saber, a filosofia negativa, da qual fazem parte seus escritos anteriores, e a filosofia positiva inaugurada em Erlangen. Essa divisão não aparece sem colocar grandes questões para o conjunto de seu pensamento. Qual o sentido então que podemos atribuir à divisão entre filosofia negativa e filosofia positiva que nos permita falar de um pensamento filosófico da unidade?

Se, por um lado, a filosofia positiva volta-se, no seu surgimento, contra o racionalismo, por outro, Schelling retoma aspectos de sua filosofia da natureza e da filosofia da identidade. Um duplo movimento que suscitou, como dissemos, várias polêmicas e reações. Schelling tanto foi acusado de pregar o irracionalismo como aqueles que o defendiam viram no resgate de elementos da sua filosofia anterior uma volta atrás do filósofo na tentativa de amenizar as críticas. Entre seus intérpretes, a dificuldade não foi menor, como nos lembra Tilliette (ibidem, p. 66), a maior parte deles ou rejeitou a divisão ou procurou uma significação extrínseca para ela.

Nesse duplo movimento, podemos, portanto, identificar não somente uma distinção entre a filosofia positiva e a filosofia negativa, mas também um movimento que parece tentar uni-las de alguma forma. É verdade que, em grande parte do período de Munique, a filosofia negativa aparece subjugada à filosofia positiva, esta última destacada por sua originalidade e autonomia (ibidem, p. 55). No entanto, ao que parece, Schelling precisou separar as duas filosofias, delimitar fronteiras, a fim de conseguir novamente uni-las, reconciliar as partes que se viram afastadas ao longo da história da filosofia. Embora relacionada com a experiência, a filosofia positiva não deixa de envolver o pensamento e a razão em seu desenrolar; só que, como nos afirma Tilliette (ibidem, p. 50),

a filosofia positiva não parte do conceito de Deus, ela deve mesmo deixá-lo de lado. Esse conceito e todo conceito. Ela tem por origem o que é antes de todo pensamento e acima de todo pensamento: o ser imemorial, o existente necessário, o Prius inconceitualizável. Mas esse impensável é o começo do pensamento. Ele faz que a filosofia - na linha positiva - se volte em direção ao pensamento e ao conceito.

Desta maneira, Tilliette (ibidem, p. 56) defende a ideia de que, ao lado da representação de duas filosofias separadas que se restabelecem em uma unidade contrastada, temos viva a ideia de uma só filosofia. Assim, poderíamos afirmar que o começo da filosofia positiva não marca o fim da filosofia negativa.

Nesse mesmo sentido, Leyte (1998, p. 11) vê as diferentes fases da filosofia de Schelling como sucessivas apresentações do mesmo problema, qual seja, a dualidade que domina todo o saber acerca do ser. Ou seja, a divisão 
entre a filosofia negativa e a filosofia positiva apresentaria a própria dualidade presente na história da filosofia.

Logo, a distinção entre as duas filosofias não estaria em contraposição ao pensamento da unidade, mas, ao contrário, contribuiria para o estabelecimento dessa unidade. Assim, Leyte propõe que as diferentes fases do pensamento de Schelling sejam entendidas como épocas. No sentido de que o termo época significa, acima de tudo, sua relação com o tempo, expressando, no entender de Leyte (ibidem, p. 13), tanto a fixação inerente a cada um dos lados da oposição - quando se trata de compreender o sentido para a tradição passada como o movimento também inerente a cada lado - quando é entendido como dynamis que encontrará sua verdade no outro. Logo, a filosofia positiva trata da história, e "a história não é a dimensão empírica, contingente, independente e afastada do curso da razão, mas o caminho mesmo à razão e a partir da razão, um caminho cujo traçado é o único que existe e que por isso mesmo é o do Absoluto" (ibidem, p. 17).

Portanto, segundo Leyte, a divisão entre filosofia positiva e filosofia negativa é o reconhecimento do dar-se do Absoluto em épocas. Assim, na Spätphilosophie, o Absoluto se apresenta não como um tema a mais da filosofia, mas como um novo horizonte para a verdade, a própria filosofia em sua unidade. Não se trata aqui de um caminho bem-aventurado nem da meta piedosa de um conjunto de fiéis, nem de uma suposta verdade acessível somente aos filósofos; ao contrário, é o caminho, como veremos a seguir, que a própria consciência tem de percorrer para reconhecer sua própria personalidade e finitude (ibidem, p. 40). O Absoluto como caminho a ser percorrido reverbera no próprio caminho seguido por Schelling de uma filosofia em constante movimento, não só se deslocando pelas suas diferentes épocas, mas também pelas suas constantes reformulações, sobretudo no que diz respeito à filosofia tardia. Talvez em um esforço, como afirma Leyte, para mostrar que em uma mesma história a natureza e o homem coincidam - e que essa coincidência é precisamente Deus. Essa história poderá ser contada sob duas perspectivas diferentes: a partir da natureza ou a partir do homem. Se a perspectiva assumida for a da natureza, decorre-se uma filosofia da natureza; se contarmos a mesma história segundo a perspectiva do homem, teremos uma história da humanidade - o que Schelling quis articular com a filosofia da mitologia e da revelação (ibidem, p. 37). Nessa história, na qual coincidem natureza e homem, contada sob a perspectiva do homem - perspectiva que caracteriza a Spätphilosophie -, veremos de que forma o Absoluto relaciona-se com o caminho percorrido pela própria consciência e, ao mesmo tempo, 
coincide com ela. $\mathrm{O}$ início desse processo, que põe em relação Absoluto e consciência humana, será descrito por Schelling na Filosofia da mitologia.

À primeira vista, pode realmente parecer estranho que o filósofo da Filosofia da Natureza e da Filosofia da Identidade venha, no período tardio de seu pensamento, a se deter nas histórias aberrantes dos chamados povos primitivos. $\mathrm{O}$ interesse pela mitologia se mostrou desde os seus primeiros escritos, mas talvez somente na sua fase tardia ele tenha percebido de que forma ela fazia parte de seu pensamento. Os estudos sobre mitologia não só inauguram a filosofia positiva como determinam tudo o que veio depois em seu pensamento. Como o próprio Schelling esclarece, não foi nem o acaso nem a intenção de se lançar em uma disciplina nova, aparentemente estranha a seus trabalhos anteriores, que o levaram a abordar esse tema: "o que me fez decidir por isso é antes o laço natural que liga a investigação desse objeto às exigências as mais características, às solicitações as mais profundas de nossa época, que - se ela não se reconhece sempre claramente, ela mesma e sua tarefa - no entanto, as sente fortemente". ${ }^{2}$

$\mathrm{Na}$ sua "Introdução histórico-crítica sobre a filosofia da mitologia", Schelling se detém nas interpretações sobre a mitologia. Já que toda questão filosófica, dirá Schelling, começa pela questão da significação, o filósofo dá início então à sua exposição por essa perspectiva hermenêutica, ou seja, perguntando-se pelo sentido da mitologia. Para tanto, Schelling empenha-se em refletir sobre cada ponto de vista a respeito da explicação da mitologia; assim, em suas primeiras lições sobre a filosofia da mitologia, o filósofo passa pelo evemerismo, pelo neoplatonismo, pela explicação poética, pela personificação; dialoga sobretudo com autores contemporâneos como Christian Georg Heyne, Georg Friedrich Creuzer, Karl Orrfried Müller.

$\mathrm{Na}$ tentativa de esquematizar as grandes correntes de estudo em torno do mito, encontramos basicamente três grupos que constituem as posições filosóficas relativas à mitologia: as que recusam todo valor de verdade ao mito; as que concedem uma verdade indireta e exterior; e as que acordam uma verdade intrínseca e imediata. ${ }^{3} \mathrm{O}$ primeiro grupo vê no mito uma tentativa de explicação do mundo, ou seja, o mito seria a personificação de fenômenos naturais. O segundo grupo via a mitologia pagã como uma caricatura das verdades da Revelação judaica. Nesse sentido, o monoteísmo estaria presente no início da humanidade, mas esta não soube mantê-lo, dando assim origem

2 Schelling, SW, XII, p. 141. As traduções das passagens de SW, XII, utilizadas ao longo deste artigo, foram baseadas na tradução francesa do texto de Schelling feita por Alain Pernet.

3 Essa síntese é apresenta por Pepin, pp. 33 et seq. 
aos diferentes deuses. A teoria tradicionalista, terceiro grupo, vê um estado de perfeição original progressivamente adulterado, sendo de ordem linguística a causa dessa deformação; nessa perspectiva, a mitologia surge de uma deficiência da linguagem capaz de gerar ambiguidade.

Portanto, os estudos sobre o mito, surgidos sobretudo ao longo do século XIX, propunham a existência de algo obscuro, algo dito nas entrelinhas das narrativas que necessitava de uma interpretação. O objetivo de Schelling ao tratar das diferentes interpretações está em mostrar como estas são insuficientes para explicar o fenômeno em sua essência. Nesse sentido, o filósofo alemão será responsável por uma mudança na forma de entender as narrativas ao afirmar que o mito é uma realidade objetiva, nada tem de alegórico e que, na verdade, o mito é tautegórico, diz o que diz e da forma que diz como única maneira possível de tratar a realidade, sem poder dizer de outra maneira. Logo, não se trata de buscar um sentido oculto, as narrativas míticas já fornecem os dados necessários para sua compreensão, abrem por si sós seu sentido. Aqui aparece o conceito de tautegoria. ${ }^{4}$ Trata-se da afirmação de si mesmo, da autoexplicação. Esse princípio, presente em seu pensamento desde o período da filosofia da identidade, estará presente também na sua análise sobre a filosofia da mitologia.

Assim, temos que nos deter no sentido próprio da mitologia, ou seja, nos deter em um único pressuposto, a saber, o de que a mitologia contém sua própria história, explica-se sozinha. Como nos diz Courtine (1998, p. 13), a filosofia da mitologia responde à orientação contida na última filosofia de Schelling em direção aos fatos, ao empírico. Logo, não se trata de adotar uma explicação independente dos fatos. Schelling pretende, como ele próprio afirma na "Filosofia da mitologia", seguir o objeto desde sua origem constituindo uma teoria ao mesmo tempo filosófica e empírica, científica e histórica, desdobrando-se ela mesma sobre o objeto e com ele. Nesse sentido, dirá Schelling, "não somos nós que instalamos a mitologia, mas a mitologia que nos instalou na perspectiva a partir da qual nós consideramos a mitologia.

4 Tal conceito, apesar de não nomeado desta maneira, aparece já nas lições da Filosofia da arte (18021805), SW, V, pp. 400-401: "não que Júpiter ou Minerva signifiquem isso ou mesmo que devam significálo. Com isso, se aniquilaria toda a independência poética dessas figuras. Elas não significam isso, elas mesmas o são. As Idéias na filosofia e os deuses na arte são um e o mesmo, mas cada qual é, por si, aquilo que é, cada qual é uma visão própria do mesmo" (tradução feita por Márcio Suzuki para a edição brasileira da Filosofia da arte). Já na "Introdução", SW, XI, pp. 195-196, temos: "a mitologia não é alegórica: ela é tautegórica. Por ela, os deuses são seres que existem realmente, que não são outra coisa, não significam outra coisa, mas significam somente o que eles são" (os trechos de SW, XI, que se encontram ao longo deste artigo, foram traduzidos a partir da edição francesa). 
O conteúdo dessa conferência não é mais daqui em diante a mitologia por nós explicada, é a mitologia se autoexplicando" ( $S W$, XII, p. 139).

Logo no início da "Introdução" ( $S W, \mathrm{XI}$, p. 6), Schelling já nos dá uma pista de sua concepção a respeito da mitologia quando lembra que o termo mitologia, vindo dos gregos, designa o conjunto de suas lendas e narrativas que remontam além do tempo histórico. Mas, entre esses dois elementos diferentes - lendas e narrativas poéticas - que constituem a mitologia, existe um núcleo central, nas palavras de Schelling, uma matéria primitiva, constituída por acontecimentos e fatos de ordem tanto natural como histórica. Trata-se do mundo dos deuses. Um mundo que não é distante e estranho daquele dos humanos, ao contrário, são mundos diretamente relacionados e dependentes entre si.

Os deuses não existem de maneira abstrata, eles são mitológicos por sua natureza e desde o início seres históricos. Logo, Schelling afirmará que a mitologia deverá ser não uma ciência que se ocupa da natureza dos deuses, mas uma história dos deuses ou, como o filósofo afirma nas primeiras páginas da "Introdução", mas só explicará mais adiante, uma teogonia (ibidem, p. 7). A mitologia é apresenta por Schelling como o processo teogônico da consciência.

Vamos aqui apresentar de forma resumida ${ }^{5}$ o processo da consciência apresentado por Schelling por meio do desdobramento de potências: ${ }^{6}$ no primeiro momento, a consciência humana, original, é identificada pelo utilizado por Schelling significa poder-ser, no mesmo sentido que a dynamis aristotélica como o próprio filósofo afirma em "Monoteísmo", SW, XII, p. 114. Para deixar mais claro o significado do termo, cito a passagem de SW, XII, p. 114, segundo a tradução francesa de Alain Pernet: "Potência (dynamis) é uma expressão pelo menos tão original em filosofia quanto nas matemáticas. - Potência significa o poder-ser,

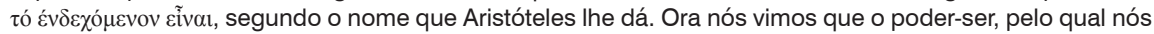
compreendemos o poder-ser imediato, a obrigação de ser e o dever-ser - são juntos poder-ser e portanto potências, mas poder-ser de ordens diversas. O poder-ser especificamente qualificado por esse nome - o [poder-ser] imediato e a obrigação de ser, apenas são poder-ser, de fato, de uma maneira indireta, enquanto o dever-ser é duplamente mediatizado, é portanto o poder-ser de terceira ordem". A tradução por "pouvoir-être" adotada por Alain Pernet talvez reduza o significado do termo. Cito aqui, portanto, a pertinente observação feita por um dos pareceristas deste artigo: "O termo original usado por Schelling desde as Vorlesungen de Erlangen, de 1821, é 'das Seinkönnende', que já naquele contexto formava uma tríade com os conceitos 'das Seinsollende' e 'das Seinmüssende' [...] ele [Schelling] usa a expressão 'das sein Könnende' e depois 'das Seinkönnende' para explicar o primeiro significado da potência, ou

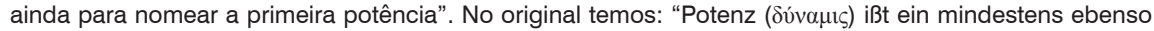
ursprünglicher Ausdruck der Philosophie als der Mathematik. - Potenz bedeutet das sein Könnende, $\tau$ ó

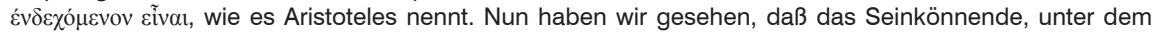
wir speziell das unmittelbar sein Könnende verstehen, das Seinmüssende und das Seinsollende, - daß diese insgesammt Seinkönnende, demnach Potenzen sind, nur Seinkönnende verschiedener Ordnung, indem das speziell so gennante - das unmittelbar sein Könnende, das Seinmüssende nur mittelbar sein Könnendes ist, das sein Sollende aber das doppelt vermittelt, also das Seinkönnende der dritten Ordnung". 
filósofo como o "poder-ser" que conduz a si mesmo, portanto, mestre de si mesmo. Ainda não temos a consciência real, mas a consciência em sua pura substancialidade; o homem não é consciência dele mesmo. A natureza humana aqui não existe por ela mesma, mas é absorvida em Deus, orientada em sua direção. Nesse momento, o homem é a "consciência de Deus, ele não tem essa consciência, ele é essa consciência, e é justamente por esse não ato, por esse não movimento que ele coloca o verdadeiro Deus" ( $S W, \mathrm{XI}, \mathrm{p}$. 187). Nessa primeira potência, a vontade se encontra em repouso. Assim, Schelling estabelece o fundamento da relação entre a consciência e Deus além da consciência real. Além dessa última, portanto, temos o momento no qual a consciência substancial coloca Deus.

Essa postulação de Deus, por sua vez, é um ato em conformidade com sua própria essência e não o resultado de um ato sabido ou desejado. Segundo Schelling, essa relação essencial só pode ser um momento, no qual o homem não pode se manter nesse ser-fora-de-si, ele deve procurar se separar dessa absorção em Deus, para transformá-la em um saber, em um conhecimento de Deus, dito de outra maneira, em uma relação fundada sobre a liberdade (ibidem, p. 189). Essa primeira potência, que é a própria consciência de Deus, ocupa esse lugar sem o merecer, o que faz com que tenhamos aqui, na perspectiva schellinguiana, um momento contingente. À consciência que somente contingentemente foi colocada como mestre de si é apresentada a possibilidade - que se encontra escondida nela - de emergir para fora da pura substancialidade.

Portanto, esse poder-ser mestre de si é um ser contingente, que esconde a possibilidade de se sobrelevar, de ser outro. Essa ambiguidade não pode permanecer segundo o que Schelling nomeia como a lei universal do mundo. Trata-se da Némesis, a potência que não está submetida à contingência e que não está em acordo com o ser indeciso, ou seja, aquele que é fortuitivamente o que é, sem o merecer. Tal potência exige que toda indecisão seja desfeita, que nada permaneça escondido, que tudo seja manifesto, claro e determinado. Em virtude dessa lei do mundo, é preciso que ao poder-ser mestre de si, que à vontade até então em repouso, seja mostrada a possibilidade que the é inerente, sem que ele o saiba ou o queira (SW, XII, p. 143). É Némesis que mostra ao ser que é fortuitamente, ao ser que é mestre de si sem o merecer, a possibilidade de se elevar da pura substancialidade. Passamos a ter, portanto, a possibilidade mesma enquanto se apresentando efetivamente à consciência. Essa possibilidade é, no entanto, enganosa, é, como nos diz Schelling, a 
apáte $^{7}$ que encontramos nos versos de Hesíodo, não uma mentira ou uma ilusão qualquer, mas a Primeira Ilusão, aquela que é origem de todas as outras (SW, XII, p. 148). Schelling identifica a apáte hesiódica com a Maya indiana. Assim é essa possibilidade que se apresenta à consciência, pois ela o faz como se a consciência pudesse manter seu estado original, ela se apresenta como uma magia enganosa.

Por último, temos a vontade, até então imóvel, desejando o ser que lhe foi mostrado e, portanto, deixando efetivamente o poder-ser que ela é. Como afirma Schelling, desse acontecimento não podemos mais nada afirmar, somente que ele se produziu, ele é o fato primordial, o começo da história, o factum, o acontecimento primordial (Urereignis). Só podemos afirmar isso por suas consequências, pelo movimento que a consciência se viu obrigada a seguir. Ele é, em relação à consciência humana real, efetiva, o acontecimento primordial. Schelling nomeia esse acontecimento como fatalidade imemorial (Unvordenkliche Verhängnis); imemorial porque é o acontecimento antes do qual a consciência nada pode se lembrar, somente as consequências ficarão; é fatalidade porque a vontade é surpreendida pela consequência não intencional, não desejada e não esperada de seu ato. Ela acreditava poder permanecer o que era segundo a possibilidade, permanecer no seu estado original. Assim, esse ato faz surgir a consciência efetiva, não mais a pura substancialidade; ela não é consciente do ato que a gerou porque é alterada completamente por esse ato que a separa de sua condição anterior.

Portanto, esse primeiro movimento da consciência efetiva se distancia do Um absoluto; a alteração pela qual a consciência passa consiste no fato de que agora faz parte dela o relativamente Um. A consciência se encontrará a partir de então submetida à sucessão necessária de representações que constitui o verdadeiro politeísmo. A mitologia é, desta maneira, para Schelling, um processo teogônico, um movimento vivido, um processo que tem origem em uma relação essencial entre a consciência humana e Deus. Os produtos desse processo teogônico serão representações. $\mathrm{Na}$ perspectiva schellinguiana, a mitologia repousa sobre a presença imediata de potências teogônicas efetivas, é o conflito de forças originais, teogônicas em si mesmas, que produz na consciência humana as representações mitológicas (ibidem, p. 130).

A teogonia constitui-se assim como o principal elemento da mitologia e seu subjectum deve ser procurado, como Schelling tenta demonstrar ao longo da "Introdução", não na imaginação dos poetas ou fruto da invenção de

7 Apaté, apresentada por Hesíodo como uma das divindades primordiais, é, assim como Nêmesis, filha da Noite. "Teogonia", v. 224 et seq. 
qualquer indivíduo, mas na consciência humana. O que não siginifica que as representações sejam subjetivas, mas, ao contrário, são da ordem do objetivo, do real; as representações engendradas na consciência serão potências divinas em suas diversas constelações e modificações (Schüssller, 1994, p. 141).

Poderíamos nos perguntar por que a consciência tem que passar por esse longo processo teogônico até se encontrar novamente com o Absoluto em sua unidade. A resposta encontra-se nessa lei universal do mundo que obriga que nada fique indeciso ou ambíguo. Se existe a possibilidade, ela, necessariamente, terá que se realizar, caso contrário não seria uma real possibilidade. $\mathrm{Na}$ perspectiva de Schelling, a possibilidade não pode permanecer em latência, ela deve transformar-se em ato.

A mitologia apresenta-se assim como "a longa história do deus que vai acabar no deus que vai vir: procura do deus perdido e o apego aos seus vestígios" (Tilliette, 2002, p. 73). O Um absoluto, o Deus único se manifestará por meio da revelação. Desta maneira, o processo teogônico da consciência começa com a filosofia da mitologia e encontra seu fim na filosofia da revelação.

Para sua Spätphilosophie, o Absoluto, como vimos, é o ponto de partida, é o Um absoluto que está presente na consciência primordial e que será encontrado no fim do processo, após ter perdido sua unidade e ter sido buscado em diferentes representações mitológicas. O processo teogônico da consciência foi considerado por muitos críticos de Schelling como um devaneio místico. Contra eles, Schelling afirma que, se o paganismo não tivesse apresentado nenhuma realidade, teria sido assim também com o Cristianismo:

\footnotetext{
por outro lado, se é verdade que o processo no qual o homem se encontrou engajado pela sequência de sua saída da relação original, dito de outra maneira, se o processo mitológico foi não um simples objeto de representação, mas um processo real, deve ser não menos verdadeiro que ele só pôde ser superado e substituído por um processo igualmente real. ( $S W, \mathrm{XI}$, p. 247)
}

A filosofia tem, portanto, um desafio e uma tarefa, como o próprio Schelling nos diz, dignos de sua época. O filósofo alemão termina a "Introdução" afirmando que, dado que nenhuma filosofia aceita e professada está no nível do fenômeno que lhe interessa, não será, de maneira alguma, o fenômeno que deverá se reduzir a uma filosofia existente, mas, ao contrário, é a filosofia que deverá ultrapassar seus limites atuais. Ou ainda, na "Filosofia da mitologia", Schelling ( $S W$, XII, p. 140) afirma:

enquanto a filosofia considerar que a condição atual das coisas e da consciência humana em geral é a medida universal e a única válida, considerando essa condição 
como necessária e eterna no sentido lógico, ela não poderá compreender nada do que ultrapassa, do que transcende a condição atual da consciência humana.

A filosofia, portanto, tem como tarefa ultrapassar seus limites atuais para ser capaz de compreender não só o fenômeno da mitologia, mas todo processo teogônico da consciência que se apresenta como o próprio caminhar do Absoluto.

\section{Referências}

COURTINE, J.-F. "Extase de la raison. Essais sur Schelling”. Paris: Galilée, 1990. . "Avant-propos". In: F. W. Schelling. Introduction à la philosophie de la mythologie. Paris: Gallimard, 1998.

COURTINE, J.-F., MARQUET, J.-F.(dir). "Le dernier Schelling: raison et positivité". Paris: Vrain, 1994.

LEYTE, A. "Las épocas de Schelling”. Madrid: Akal, 1998.

PEPIN, J. "Mythe et allégorie". Paris: Études Augustiniennes, 1976.

REY PUENTE, F., VIEIRA, LA. (org.). "As filosofias de Schelling”. Belo Horizonte: Ed. UFMG, 2005.

SCHELLING, F. W. "Introduction à la Philosophie de la Mythologie". Tradução sob direção de Jean-François Courtine e Jean-François Marquet. Paris: Gallimard, 1998. . "Le Monothéisme". Tradução de Alain Pernet. Paris: Vrin, 1992.

."Philosophie de la Mythologie". Tradução de Alain Pernet. Grenoble: Millon, 1994.

. "Sämtliche Werke". Augsburg/Stuttgart: Cotta, 1856-1861.

SCHÜSSLLER, I. "La mythologie comme processus de la conscience dans la Philosophie de la mythologie de Schelling”. In: J.-F. Courtine, J.-F. Marquet (dir.). Le dernier Schelling: raison et positivité. Paris: Vrain, 1994.

TILLIETTE, X. "La mythologie comprise: Schelling et l'interprétation du paganisme". Paris: Vrin, 2002.

. "Schelling: Une philosophie en devenir". Paris: Vrin, 1992. 